\title{
Editorial Expression of Concern: The bio-mitigation of acetochlor in soil using Rhodopseudomonas capsulata in effluent after wastewater treatment
}

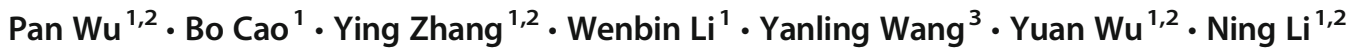 \\ Published online: 28 November 2020 \\ (C) Springer-Verlag GmbH Germany, part of Springer Nature 2020
}

Editorial Expression of Concern: J Soils Sediments 19, 2927-2933 (2019) https://doi.org/10.1007/s11368-018-2201-2

The Editors-in-Chief would like to alert readers that concerns have been raised regarding the authorship and data in this article (Wu et al. 2019). Authors Ying Zhang and Bo Cao state that they had no knowledge of the article and did not agree to its publication. In addition to this, the corresponding author has not been able to provide the raw data for this article. Because of these concerns, the Editors-in-Chief urge readers to interpret the results with caution. Pan Wu and Ying Zhang have agreed to this editorial expression of concern. Bo Cao, Wenbin Li, Yanling Wang, Yuan $\mathrm{Wu}$ and Ning Li have not responded to any correspondence from the editor/publisher about this editorial expression of concern.

\section{Reference}

Wu P, Cao B, Zhang Y et al (2019) The bio-mitigation of acetochlor in soil using Rhodopseudomonas capsulata in effluent after wastewater treatment. J Soils Sediments 19:2927-2933. https://doi.org/10.1007/ s11368-018-2201-2

Publisher's note Springer Nature remains neutral with regard to jurisdictional claims in published maps and institutional affiliations.

The original article can be found online at https://doi.org/10.1007/ s11368-018-2201-2.

Bo Cao

18340873503@163.com

1 School of Resources and Environment, Key Laboratory of Soybean Biology in Chinese Education Ministry, Northeast Agricultural University, Harbin 150030, China

2 School of Environment and Resources, Dalian Minzu University, Dalian 116600, China

3 Department of Anesthesiology, The Third Affiliated Hospital of SunYat-Sen University, Guangzhou 510630, China 